\title{
Association Study of Two Functional Single Nucleotide Polymorphisms of Neuropeptide Y Gene with Multiple Sclerosis
}

\author{
Seyed Mahdi Mohammadi ${ }^{1}$, Zeinab Shirvani Farsani ${ }^{1}$, Rozita Dosti ${ }^{2}$, Mohammad Ali \\ Sahraian ${ }^{2}$, Mehrdad Behmanesh ${ }^{1 .}$
}




\section{Abstract}

Multiple sclerosis (MS) is an autoimmune disease of the central nervous system characterized by brain inflammation, demyelination and axonal loss. Neuropeptide Y (NPY) has a critical role in the maintenance of homeostasis in the immune system and coping of stress condition. In current study we analyzed 188 patients suffering from MS and 204 unrelated healthy controls for two functional single nucleotide polymorphisms (SNPs), NPY _20T $>\mathrm{C}$ (rs16139) and NPY _-485T $>$ C (rs16147) using PCR-RFLP and Mismatch PCR-RFLP methods. Our results demonstrated that homozygocity in the minor allele for $N P Y \quad-485 \mathrm{~T}>\mathrm{C}$ polymorphism is associated with the MS risk in patients in compare with healthy controls (CC vs. TT, $P=0.033$; $\mathrm{CC}$ vs. TT $+\mathrm{TC}, P=0.02$ ). In addition, by comparison with allele T, the frequency of NPY _-485C allele was higher in cases than in control subjects and present increased risk of MS, but statistically significant was borderline $(P=0.053)$. The stratification for disease progression revealed a significant difference in the allelic and genotypic distribution between subgroups of MS and controls. The frequency of the CC genotype and C allele was higher in the primary progressive MS patients when compared with control group (CC vs. TT, $P$ $=0.019 ; \mathrm{CC}$ vs. TT $+\mathrm{TC}, P=0.008 ; \mathrm{C}$ vs. T, $P=0.022)$. In addition, the frequency of $\mathrm{CC}$ genotype was higher in the relapsing remitting MS patients when compared with control group (CC vs. TT, $P=0.034 ; \mathrm{CC}$ vs. TT + TC, $P=0.016$ ). Haplotype analysis demonstrated that the haplotype $3(\mathrm{CT})$ is more common in RR MS $(P=0.041)$, and PP MS $(P=0.031)$ than control group. In conclusion, obtained results demonstrate the probable role of NPY SNPs in susceptibility to MS within the Iranian population. 
Keywords: Multiple sclerosis; Neuropeptide Y; Autoimmune disease; SNP; Genotyping

1. Introduction

Multiple sclerosis is one of the most common demyelinating diseases of the central nervous system (CNS). The majority ( $\sim 85 \%)$ of MS patients are initially diagnosed with relapsing remitting (RR). RR MS patients experience alternating periods of neurological disability and recovery that can last for many years (Dutta and Trapp, 2012). About 50\% of RR MS patients will subsequently develop secondary progressive (SP) disease course, which steady neurological decline is main characteristic of SP MS. In 10-15\% of MS cases, disease is progressive from the outset and is termed primary progressive MS (PP-MS) (Debouverie et al., 2008).

Geographical distribution and migration studies suggest a considerable contribution of environmental factors in susceptibility to MS (Ebers, 2008; Farsani et al., 2015), but twins and sibling epidemiological studies indicated that genetic factors play a significant role in determining who develops MS (Hoffjan and Akkad, 2010; Ramagopalan et al., 2010). Two main groups of high-throughput genotyping analyses: candidate gene approaches and genome-wide association studies (GWAS) have identified polymorphisms in the human leukocyte antigen (HLA) region as the strongest susceptibility loci for MS (Schmidt et al., 2007). But more investigations have identified a broad spectrum of non-HLA genes prominently associated with MS and other autoimmune diseases (Bahadori et al., 2015). This studies revealing a vulnerability locus on the human chromosome $7 \mathrm{p} 15$, a locus that actually encodes $N P Y$ as a non-HLA gene (Becker et al., 1998; Bedoui et al., 2004a).

$N P Y$, a 36 amino acid peptide, was discovered in 1982 by Tatemoto and has since been found to be present in various brain regions, where it is implicated in various CNS functions. In 
the periphery, $N P Y$ is released from sympathetic nerves alone and in combination with catecholamines (Hörsten et al., 2004). Interestingly, NPY has been implicated in a multitude of immunological functions and mechanisms (Bedoui et al., 2004b). NPY, as a most abundant neuropeptides in the central and peripheral nervous system (Dimitrijevic and Stanojevic, 2013; Gray and Morley, 1986) moderates powerful immunological actions in vitro and in vivo, such as sytokines and oxidative agents production and release, natural killer (NK) cells activation, $\mathrm{T}$ helper (Th) cells differentiation, B cells regulation, and trafficking and migration of leukocytes (Bedoui et al., 2003; Dimitrijevic and Stanojevic, 2013; Farzi et al., 2015).

$N P Y$ participates in the regulation of multiple physiological processes, including vasoconstriction, energy balance, feeding and anxiety, all of which are mediated through five different NPY G-protein-coupled receptors (Y1, Y2, Y4, Y5 and y6) (Prod'homme et al., 2006).

$N P Y \_20 \mathrm{~T}>\mathrm{C}$ results in leucine (Leu) 7 to prolein (Pro) 7 substitution in the signal peptide part of prepro-NPY (Karvonen et al., 1998). The substitution alters the properties of the signal peptide due to the different physicochemical properties of Leu and Pro amino acids and potentially quantity of NPY protein (Kallio, 2001). The signal peptide guides preproNPY into endoplasmic reticulum (ER). In the ER, the signal peptide is cleaved off and the remaining proNPY undergoes further modification into mature 36-residue amidated NPY, which is stored in secretory vesicles (Paquet et al., 1996). It is proposed that the secondary and tertiary structures of the signal peptide may be dramatically altered by the Leu7Pro substitution, since proline simply forms brakes and kinds in alpha-helical structures. Therefore this polymorphism may alter the formation, storage, and release of the mature NPY (Fitches et al., 1998; Ryan and Edwards, 1995). Expression analyses show that the C-allele in the NPY promoter variant - 
$485 \mathrm{~T}>\mathrm{C}$ is associated with higher $N P Y$ expression levels in the brain. This finding was confirmed by electrophoretic mobility shift assay, demonstrating that the C-allele has strongly reduced affinity for a yet unknown factor compared to the T-allele (Sommer et al., 2010).

Therefore, according to the many effects of NPY in immune system homeostasis and functional roles for $N P Y \_20 \mathrm{~T}>\mathrm{C}$ and $N P Y{ }_{-}-485 \mathrm{~T}>\mathrm{C}$, current study analyzed the association of these two SNPs with MS, as autoimmune disease, in Iranian population. The study of NPY polymorphisms provides a novel insight into the role of $N P Y$ in MS etiology.

2. Materials and methods

\subsection{Patients and controls}

We studied 188 MS patients with definite MS according to McDonald's criteria (Poser et al., 1983). The patients had RR, SP or PP course were recruited from Multiple Sclerosis centers at Sina Hospital (Tehran, Iran). The mean age of the patients was $34 \pm 8.96$ years, and mean EDSS (McDonald et al., 2001) was 3.12 \pm 2.00 . The control group was selected from healthy volunteers matched according to sex and age. They had no evidence or family history of autoimmune disease or multiple sclerosis. All the participants signed a written informed consent prior to the blood sampling and Tarbiat Modares University ethical committee approved the study (d52/6723).

\subsection{DNA Extraction}

Genomic DNA was extracted from blood samples using DNP ${ }^{\mathrm{TM}}$ Kit (CinnaGen, Iran) based on producer instruction. Briefly, lysis solution was used to lyse blood cells and then genomic DNA from white cells selectively precipitated by isopropanol. The precipitated DNA was 
washed and desalted by $70 \%$ ethanol and dissolved in TE buffer and stored in $-80^{\circ} \mathrm{C}$ till molecular analysis. Quality and quantity of the extracted DNA were examined by spectrophotometer or visualized by electrophoresis in $1 \%$ agarose gel, respectively.

\subsection{SNPs Genotyping}

50-100 ng of purified genomic DNA used for genotyping. The polymorphism of NPY $\_20 \mathrm{~T}>\mathrm{C}$ was determined by a specific primers set of (Forward: 5'TCTGCGGGACTGGGACGAGAGC-3' $3^{\prime}$ and $5^{\prime}$ TTGATGTAGTGTCGCAGCGCCGAGT-3') and PCR-RLFP method. These primers for NPY 20T $>$ C SNP amplified a fragment with 308 bp length.

Since there is no restriction site in $N P Y{ }_{-}-485 \mathrm{~T}>\mathrm{C}$ SNP site, a specific mismatched forward primer of 5'-CAGGTGCTTCCTACTCCGGCGCCCAG-3' and Reverse primer: 5'CGACTTAGGGAGCCACCCACACC-3' were designed to introduce a Bgl I restriction site in the mutant allele site (Figure 1) for genotyping with a mismatch PCR- RLFP technique. Specific primers were designed by Oligo Primer Analysis software version 7.

The amplification was performed using master mix PCR (Solis BioDyne, Stonia) through following instruction: an initial denaturation at $95{ }^{\circ} \mathrm{C}$ for $5 \mathrm{~min}$, followed by 40 cycles of denaturation at $95{ }^{\circ} \mathrm{C}$ for $30 \mathrm{sec}$, and annealing at $58^{\circ} \mathrm{C}$ for $50 \mathrm{sec}$, extension at $72{ }^{\circ} \mathrm{C}$ for $1 \mathrm{~min}$ and a final extension step of $5 \mathrm{~min}$ at $72^{\circ} \mathrm{C}$. PCR products were digested with BsrI (Fermentas) or BgII (Takara Bio Inc, japan) restriction enzymes in a total volume of $20 \mu \mathrm{L}$ at $37{ }^{\circ} \mathrm{C}$ for an overnight according to manufacturer's instruction. Digested fragments were subjected to electrophoresis on $12 \%$ polyacrylamide gel. 
To verify the designed genotyping procedures the DNA sequences of some randomly selected samples for each genotype, was determined by an ABI automated DNA sequencer (Macrogen, Korea).

\subsection{Statistical Analysis}

Statistical calculations were performed by SPSS software package (Version.19.0). The Chisquare test was used to analyze the association of two SNPs with MS using frequency of allele and genotype between the studied groups. We chose a significance level of 0.125 using Bonferroni's correction to gain the conventional $p$-value of $\leq 0.05$ as overall significant level. Moreover, odds ratio and 95\% confidence interval (CI) were estimated for both the patient and healthy controls. The Hardy-Weinberg equilibrium also was evaluated using the Chi-square test. Frequencies of haplotypes were estimated using the PHASE (version 2.1.1) software. The differences in frequencies were tested by the Chi square test.

\section{Results}

In current study, we used mismatch PCR-RFLP and PCR-RFLP methods for genotyping NPY _485T $>\mathrm{C}$ SNP and NPY_20T $>\mathrm{C}$ SNP, respectively. Then we recognized different genotypes of individuals by analysis of digested product on $12 \%$ acrylamide gel (Figure 2 and 3). Genotyped results were matched with sequencing results according to used methods (Figure 4).

\subsection{Association analysis of individual SNPs}

Demographic characteristics of MS patients and controls are summarized in Table 1. The frequencies of two SNPs were in Hardy-Weinberg Equilibrium in both patient and control groups. The alleles frequency and genotypes distribution for the $N P Y{ }_{-}-458 \mathrm{~T}>\mathrm{C}$ and $N P Y$ 
$20 \mathrm{~T}>\mathrm{C}$ in cases and control subjects were compared (Table 2). The frequency of the NPY _485CC genotype was higher among cases when compared with healthy control subjects. We found that the $N P Y{ }_{-}-485 \mathrm{CC}$ genotype is significantly associated with the increased risk of MS $(\mathrm{CC}$ vs. $\mathrm{TT}, \mathrm{OR}=1.866,95 \% \mathrm{CI}=1.047-3.333, P=0.033 ; \mathrm{CC}$ vs. $\mathrm{TT}+\mathrm{TC}, \mathrm{OR}=1.825,95 \%$ $\mathrm{CI}=1.094-3.046, P$ value $=0.02)$. In addition, by comparison with allele $\mathrm{T}$, the frequency of $N P Y \_-485 \mathrm{C}$ allele was higher in cases than in control subjects and present increased risk of MS $(\mathrm{OR}=1.323,95 \% \mathrm{CI}=0.996-1.756)$, But statistically significant was borderline $(P=0.053)$. The comparisons between the cases and control subjects demonstrated that the allelic and genotypic frequencies of $N P Y \_20 \mathrm{~T}>\mathrm{C}$ polymorphism did not show statistically association with MS.

\subsection{The analysis of $N P Y_{-}-485 \mathrm{~T}>\mathrm{C}$ frequency in three types of $\mathrm{MS}$}

In this study the relationship between the $N P Y_{-}-485 \mathrm{~T}>\mathrm{C}$ SNP and three subtypes of MS were analyzed (Table 3). The stratification for disease progression revealed a significant difference in the allelic and genotypic distribution between PP MS patients and controls and the genotypic distribution between RR MS patients and controls (Table 3). The frequency of the CC genotype was higher in the PP MS group when compared with control group (CC vs. TT, OR = 9.467, 95\% CI $=1.015-88.258, P=0.019 ; \mathrm{CC}$ vs. $\mathrm{TT}+\mathrm{TC}, \mathrm{OR}=5.800,95 \% \mathrm{CI}=1.375-$ 24.457, $P=0.008)$. Also a more prevalent of $\mathrm{C}$ allele was observed in PP MS group than control group $(\mathrm{OR}=3.307,95 \% \mathrm{CI}=1.128-9.694, P=0.022)$. In addition, the frequency of $\mathrm{CC}$ genotype was higher in the RR MS patients when compared with control group (CC vs. TT, OR $=1.936,95 \% \mathrm{CI}=1.049-3.576, P=0.034 ; \mathrm{CC}$ vs. $\mathrm{TT}+\mathrm{TC}, \mathrm{OR}=1.933,95 \% \mathrm{CI}=1.126-3.320$, $P=0.016)$. 


\subsection{Haplotype-based association analysis}

Haplotypes of two genotyped SNPs for association with MS susceptibility were analyzed. In our data set, three common haplotypes were found. There was no significant association between these haplotypes and MS when compared with control group (Table 4). But considering MS subtypes, haplotype 3 (CT) was more common in RR MS (OR $=1.363,95 \% \mathrm{CI}=1.013-1.834, P$ $=0.041)$, and PP MS $(\mathrm{OR}=3.096,95 \% \mathrm{CI}=1.056-9.076, P=0.031)$ than control group.

\section{Discussion}

This study presents additional evidence for an important role of $N P Y$ gene in MS pathogenesis and disease progression. It seems obtained result is consistent with previous studies showing possible involvement of NPY system in autoimmune disorder such as MS. By comparing of the genotype and allelic frequency of $N P Y{ }_{-}-485$ polymorphism in patient and control group, we found that the increased risk for MS is seen with CC genotype (Table 2). In addition, there was a tendency toward association of $\mathrm{C}$-allele with susceptibility to $\mathrm{MS}(P=$ 0.053). Also a significant difference was observed in genotype and allelic frequencies of this SNP between PP MS subgroup and control group (Table 3). The CC genotype was higher in RR MS than control group (Table 3).

Several studies have shown that $N P Y{ }_{-}-485 \mathrm{~T}>\mathrm{C}$ is a functional SNP that can regulate the transcriptional activity of the gene. Itokawa et al. by an in vitro promoter assay using IMR-32 cells and COS-1 cells, demonstrated that $-485 \mathrm{~T}$ allele has a reduced transcriptional activity (Itokawa et al., 2003). Buckland et al. reported similar results in different two cell lines of 
HEK293t and TE671 as well. (Buckland et al., 2004). Electrophoretic mobility shift assay shown that the C-allele has strongly reduced affinity for a yet unknown factor compared to the T-allele. In addition, analyzing 107 human post-mortem brain samples shown that allelic variation at this SNP contributes to regulation of $N P Y$ mRNA and peptide levels in this region. Specifically, the C- allele leads to increased gene expression (Sommer et al., 2010).

It is well established that the sympathetic nervous system (SNS) and the immune system communicate functionally witch each other. The SNS modulate immune response in a bimodal manner: on the one hand there is a strong anti-inflammatory branch, whereas on the other hand the SNS also exerts pro-inflammatory action. Interestingly, studies have indicated that the crosstalk between the SNS and the immune system is substantially disturbed in Th1-medited autoimmune disease such as rheumatoid arthritis (RA) and MS (Bedoui et al., 2004a). This crosstalk mediated by several neurotransmitters that $N P Y$ is one of the most important of them. $N P Y$ directly increases the release of oxygen radicals in murine peritoneal monocytes. The combined action of NPY and catecholamines through $\beta$-adrenoceptors intensifies the increased interleukin (IL)-6 release. NPY induces a preferential mobilization of activated monocytes through increased chemotaxis and increased overall avidity of adhesion molecule receptor on lymphocytes (Bedoui et al., 2003; Buttari et al., 2014). Previous studies have shown that NPY augments the $\beta 1$ integrin mediated adhesion of human $\mathrm{T}$ cell to fibronectin, a major glycoprotein component of the extracellular matrix, and mediates $\mathrm{T}$ cell migration from the blood into the brain (Dimitrijevic and Stanojevic, 2013). Among all pro-inflammatory effects, it seems activation of antigen presenting cells (APCs) is the main effect of NPY on the immune system. Y1-deficient macrophages and dendritic cells secret less IL-12 and tumor necrosis factor $\alpha$ 
(TNF- $\alpha$ ) than wild type APCs (Prod'homme et al., 2006).The interaction between APCs and Tcell is a key effector of inflammatory injury in MS (Weiner, 2008). It has been demonstrated that, the blocking this interaction modulates immune responses in experimental autoimmune encephalomyelitis (EAE), animal model of MS, thus ameliorating disease (Jonker et al., 1988). Levy-Barazany and Frenkel reported that scavenger receptor A (SAR)-deficient APCs had an impaired ability to drive production sytokines that play pivotal roles in EAE, including IL-2, IL17, interferon gamma, TNF- $\alpha$ and IL-6. Therefore SAR-deficiency led to reduction in EAE disease progression (Levy-Barazany and Frenkel, 2012). IL-6 as one of the targets of NPY induces the development of Th-17 cells from naïve T cells and inhibits T regulatory (Treg) cell functions (Kimura and Kishimoto, 2010; Oukka, 2007). Th-17 cells are a key player in the pathogenesis of autoimmune diseases, while Treg cells play a critical role in maintaining immune self-tolerance (Astry et al., 2015). According to Zhang and et al. study, silencing of miR26a, an IL-6 associated miRNA, increased Th-17 related responses and severity of EAE, while overexpression of miR26a reduced Th-17 related responses and resulted a milder form of EAE (Zhang et al., 2015).

According to our data the increased risk of MS is associated with NPY _-485CC genotype. Also, this genotype and C-allele are very prevalent in PP MS subgroup than control group. As previously mentioned, this SNP is located in the prompter and increases the expression of NPY gene. Therefore we speculated that pro-inflammatory effects of $N P Y$ especially effects on APCs might be involved in susceptibility to MS and severity of symptoms disease. The identification of the pro-inflammatory effects of $N P Y$ on APCs might reduce the potential application of $N P Y$ and NPY analogs in the treatment of Th1-mediated autoimmune conditions, including MS and 
RA. In this regard, although $N P Y$ prevented the induction of acute EAE by inhibiting Th1 responses, it could not reverse chronic EAE, a phase of disease in which activated macrophages might predominate in CNS damage (Platten and Steinman, 2005; Prod'homme et al., 2006).

Moreover, $N P Y$ can influence immune system and pathogenesis of autoimmune disease by indirect manners, for example, the effects of $N P Y$ on the stress. Both genetic and pharmacological interventions support a pivotal role of $N P Y$ in promoting stress coping and resiliency (Farzi et al., 2015; Sah and Geracioti, 2013; Wagner et al., 2016). Investigations have demonstrated that the risk allele of $N P Y{ }_{-}-485 \mathrm{~T}>\mathrm{C}$ disturbs stress coping role of $N P Y$ (Sommer et al., 2010). Substantial evidence indicates stress can precipitate or worsen symptoms of inflammation in general and more specifically in MS. However, the mechanism of how stress affects MS has not been well understood, but Karagkouni et al. proposed that neuropeptides secreted under stress activate microglia and mast cell to release inflammatory molecules. These lead to maturation and activation of T17 autoimmune cells, disruption blood-brain barrier and T cell entry into the CNS, thus promoting brain inflammation and contributing to MS pathology (Karagkouni et al., 2013). In addition, the role of NPY in promoting stress coping becomes more important when we know that the disease itself causes significant stress in the patients (Stojanovich, 2010).

Main limitation of current study was its lake of power to survey amount of NPY in the serum or samples from post mortem brain tissue and cerebrospinal fluid. We could study the SNPs relation with gene expression if this limitation was eliminated.

According to our data, the association of $N P Y{ }_{-}-485 \mathrm{~T}>\mathrm{C}$ may be restricted to MS patients characterized by chronic disease progression. These differences support the concept that clinical 
phenotypes may have different etiologies and so require different therapy strategies.

In summary, this study, the first association study for $N P Y$ and MS, supports the view that $N P Y$ can be considered as a candidate gene for multiple sclerosis, specially the chronic types. Nevertheless, further studies with larger sample size are needed to confirm the exact association of $N P Y$ gene with MS.

Acknowledgments

The authors gratefully acknowledge the contribution of the patients, healthy controls for their blood donations and also institution for their help in this study. The Iran National Science Foundation and the Department of Research Affairs of Tarbiat Modares University provide the funding for this work.

\section{References}

Astry, B., Venkatesha, S.H., Moudgil, K.D., 2015. Involvement of the IL-23/IL-17 axis and the Th17/Treg balance in the pathogenesis and control of autoimmune arthritis. Cytokine 74, 54-61. Bahadori, Z., Behmanesh, M., Sahraian, M.A., 2015. Two functional promoter polymorphisms of neuregulin 1 gene are associated with progressive forms of multiple sclerosis. Journal of the neurological sciences 351, 154-159.

Becker, K.G., Simon, R.M., Bailey-Wilson, J.E., Freidlin, B., Biddison, W.E., McFarland, H.F., Trent, J.M., 1998. Clustering of non-major histocompatibility complex susceptibility candidate loci in human autoimmune diseases. Proceedings of the National Academy of Sciences of the United States of America 95, 9979-9984.

Bedoui, S., Kawamura, N., Straub, R.H., Pabst, R., Yamamura, T., von Horsten, S., 2003. Relevance of neuropeptide Y for the neuroimmune crosstalk. Journal of neuroimmunology 134, $1-11$.

Bedoui, S., Miyake, S., Straub, R.H., von Horsten, S., Yamamura, T., 2004a. More sympathy for autoimmunity with neuropeptide $Y$ ? Trends in immunology 25, 508-512.

Bedoui, S., Pabst, R., Hörsten, S., 2004b. NPY and Immune Functions: Implications for Health and Disease. 162, 409-445.

Buckland, P.R., Hoogendoorn, B., Guy, C.A., Coleman, S.L., Smith, S.K., Buxbaum, J.D., Haroutunian, V., O'Donovan, M.C., 2004. A high proportion of polymorphisms in the promoters of brain expressed genes influences transcriptional activity. Biochimica et biophysica acta 1690, 
238-249.

Buttari, B., Profumo, E., Domenici, G., Tagliani, A., Ippoliti, F., Bonini, S., Businaro, R., Elenkov, I., Riganò, R., 2014. Neuropeptide Y induces potent migration of human immature dendritic cells and promotes a Th2 polarization. The FASEB Journal 28, 3038-3049.

Debouverie, M., Pittion-Vouyovitch, S., Louis, S., Guillemin, F., Group, L., 2008. Natural history of multiple sclerosis in a population-based cohort. European journal of neurology 15, 916-921.

Dimitrijevic, M., Stanojevic, S., 2013. The intriguing mission of neuropeptide $Y$ in the immune system. Amino acids 45, 41-53.

Dutta, R., Trapp, B.D., 2012. Gene expression profiling in multiple sclerosis brain. Neurobiology of disease 45, 108-114.

Ebers, G.C., 2008. Environmental factors and multiple sclerosis. The Lancet Neurology 7, 268277.

Farsani, Z.S., Behmanesh, M., Sahraian, M.A., 2015. Interleukin-10 but not transforming growth factor- $\beta 1$ gene expression is up-regulated by vitamin $D$ treatment in multiple sclerosis patients. Journal of the neurological sciences 350, 18-23.

Farzi, A., Reichmann, F., Holzer, P., 2015. The homeostatic role of neuropeptide Y in immune function and its impact on mood and behaviour. Acta Physiologica 213, 603-627.

Fitches, A.C., Appleby, R., Lane, D.A., De Stefano, V., Leone, G., Olds, R.J., 1998. Impaired cotranslational processing as a mechanism for type I antithrombin deficiency. Blood 92, 46714676.

Gray, T.S., Morley, J.E., 1986. Neuropeptide Y: Anatomical distribution and possible function in mammalian nervous system. Life Sciences 38, 389-401.

Hoffjan, S., Akkad, D.A., 2010. The genetics of multiple sclerosis: an update 2010. Molecular and cellular probes 24, 237-243.

Hörsten, S., Hoffmann, T., Alfalah, M., Wrann, C.D., Karl, T., Pabst, R., Bedoui, S., 2004. PP, PYY and NPY: Synthesis, Storage, Release and Degradation. 162, 23-44.

Itokawa, M., Arai, M., Kato, S., Ogata, Y., Furukawa, A., Haga, S., Ujike, H., Sora, I., Ikeda, K., Yoshikawa, T., 2003. Association between a novel polymorphism in the promoter region of the neuropeptide Y gene and schizophrenia in humans. Neuroscience Letters 347, 202-204.

Jonker, M., van Lambalgen, R., Mitchell, D.J., Durham, S.K., Steinman, L., 1988. Successful treatment of EAE in rhesus monkeys with MHC class II specific monoclonal antibodies. Journal of autoimmunity 1, 399-414.

Kallio, J., 2001. Altered intracellular processing and release of neuropeptide Y due to leucine 7 to proline 7 polymorphism in the signal peptide of preproneuropeptide $\mathrm{Y}$ in humans. The FASEB Journal.

Karagkouni, A., Alevizos, M., Theoharides, T.C., 2013. Effect of stress on brain inflammation and multiple sclerosis. Autoimmunity reviews 12, 947-953.

Karvonen, M.K., Pesonen, U., Koulu, M., Niskanen, L., Laakso, M., Rissanen, A., Dekker, J.M., Hart, L.M., Valve, R., Uusitupa, M.I., 1998. Association of a leucine(7)-to-proline(7) polymorphism in the signal peptide of neuropeptide $\mathrm{Y}$ with high serum cholesterol and LDL cholesterol levels. Nature medicine 4, 1434-1437.

Kimura, A., Kishimoto, T., 2010. IL-6: regulator of Treg/Th17 balance. European journal of immunology 40, 1830-1835.

Levy-Barazany, H., Frenkel, D., 2012. Expression of scavenger receptor A on antigen presenting 
cells is important for CD4+ T-cells proliferation in EAE mouse model. Journal of neuroinflammation 9, 120.

McDonald, W.I., Compston, A., Edan, G., Goodkin, D., Hartung, H.P., Lublin, F.D., McFarland, H.F., Paty, D.W., Polman, C.H., Reingold, S.C., Sandberg-Wollheim, M., Sibley, W., Thompson, A., van den Noort, S., Weinshenker, B.Y., Wolinsky, J.S., 2001. Recommended diagnostic criteria for multiple sclerosis: guidelines from the International Panel on the diagnosis of multiple sclerosis. Annals of neurology 50, 121-127.

Oukka, M., 2007. Interplay between pathogenic Th17 and regulatory T cells. Annals of the rheumatic diseases 66 Suppl 3, iii87-90.

Paquet, L., Massie, B., Mains, R.E., 1996. Proneuropeptide Y processing in large dense-core vesicles: manipulation of prohormone convertase expression in sympathetic neurons using adenoviruses. The Journal of neuroscience 16, 964-973.

Platten, M., Steinman, L., 2005. Multiple sclerosis: trapped in deadly glue. Nature medicine 11, 252-253.

Poser, C.M., Paty, D.W., Scheinberg, L., McDonald, W.I., Davis, F.A., Ebers, G.C., Johnson, K.P., Sibley, W.A., Silberberg, D.H., Tourtellotte, W.W., 1983. New diagnostic criteria for multiple sclerosis: guidelines for research protocols. Annals of neurology 13, 227-231.

Prod'homme, T., Weber, M.S., Steinman, L., Zamvil, S.S., 2006. A neuropeptide in immunemediated inflammation, Y? Trends in immunology 27, 164-167.

Ramagopalan, S.V., Dobson, R., Meier, U.C., Giovannoni, G., 2010. Multiple sclerosis: risk factors, prodromes, and potential causal pathways. Lancet neurology 9, 727-739.

Ryan, P., Edwards, C.O., 1995. Systematic introduction of proline in a eukaryotic signal sequence suggests asymmetry within the hydrophobic core. Journal of Biological Chemistry 270, 27876-27879.

Sah, R., Geracioti, T.D., 2013. Neuropeptide Y and posttraumatic stress disorder. Molecular psychiatry 18, 646-655.

Schmidt, H., Williamson, D., Ashley-Koch, A., 2007. HLA-DR15 haplotype and multiple sclerosis: a HuGE review. American journal of epidemiology 165, 1097-1109.

Sommer, W.H., Lidstrom, J., Sun, H., Passer, D., Eskay, R., Parker, S.C., Witt, S.H., Zimmermann, U.S., Nieratschker, V., Rietschel, M., Margulies, E.H., Palkovits, M., Laucht, M., Heilig, M., 2010. Human NPY promoter variation rs16147:T $>$ C as a moderator of prefrontal NPY gene expression and negative affect. Human mutation 31, E1594-1608.

Stojanovich, L., 2010. Stress and autoimmunity. Autoimmunity reviews 9, A271-276.

Wagner, Kaestner, L., Wolf, F., Stiller, R., Heiser, H., Manhart, U., Hoffmann, S., Rahfeld, T., Demuth, J.-u., Hans-ulrich, Rothermundt, Hörsten, M., Von, S., 2016. Neuropeptides Identifying neuropeptide Y ( NPY) as the main stress-related substrate of dipeptidyl peptidase 4 ( DPP4 ) in blood circulation. YNPEP 57, 21-34.

Weiner, H.L., 2008. A shift from adaptive to innate immunity: a potential mechanism of disease progression in multiple sclerosis. Journal of neurology 255 Suppl 1, 3-11.

Zhang, R., Tian, A., Wang, J., Shen, X., Qi, G., Tang, Y., 2015. miR26a modulates Th17/Treg balance in the EAE model of multiple sclerosis by targeting IL6. Neuromolecular medicine 17, 24-34. 


\section{Figure legend:}

Figure 1: A schematic representation of designed Mismatch PCR-RFLP technique. (A) Restriction enzyme can't cut the site include T/C allelic forms of NPY_-485T $>$ C. (B) By using a forward mismatch primer, the nucleotide adjacent to SNP nucleotide is changed. (C) Introduce a restriction site for BglI enzyme that can be cut allelic form of $\mathrm{C}$ but not $\mathrm{T}$ allele.

Figure 2: Mismatch PCR-RFLP technique used for genotyping of $N P Y$ _ $485 \mathrm{~T}>\mathrm{C}$. The presence of C allele in SNP position can be recognized by BgII as a restriction endonuclease enzyme. Digestion process produces 250 and 30 bp fragments. The genotype of each sample is shown on top of the gel. Undigested control and ladder is shown by UD and M respectively.

Figure 3: PCR-RFLP technique used for genotyping of NPY_20T $>\mathrm{C}$ SNP by BsrI as a restriction endonuclease enzyme. The presence of T allele in SNP position can be recognized by this method. Digestion process produces 158 and 150 bp fragments. The genotype of each sample is shown on the top of the gel. Undigested control and ladder is shown by UD and M respectively.

Figure 4: Sequencing result of PCR product that is consistent with genotyping results of PCR-RFLP and mismatch PCR-RFLP technique. (A) Sequencing result of heterozygote sample for $N P Y{ }_{-}-485 \mathrm{~T}>\mathrm{C}$. (B) Sequencing result of heterozygote sample for $N P Y \_20 \mathrm{~T}>\mathrm{C}$. 

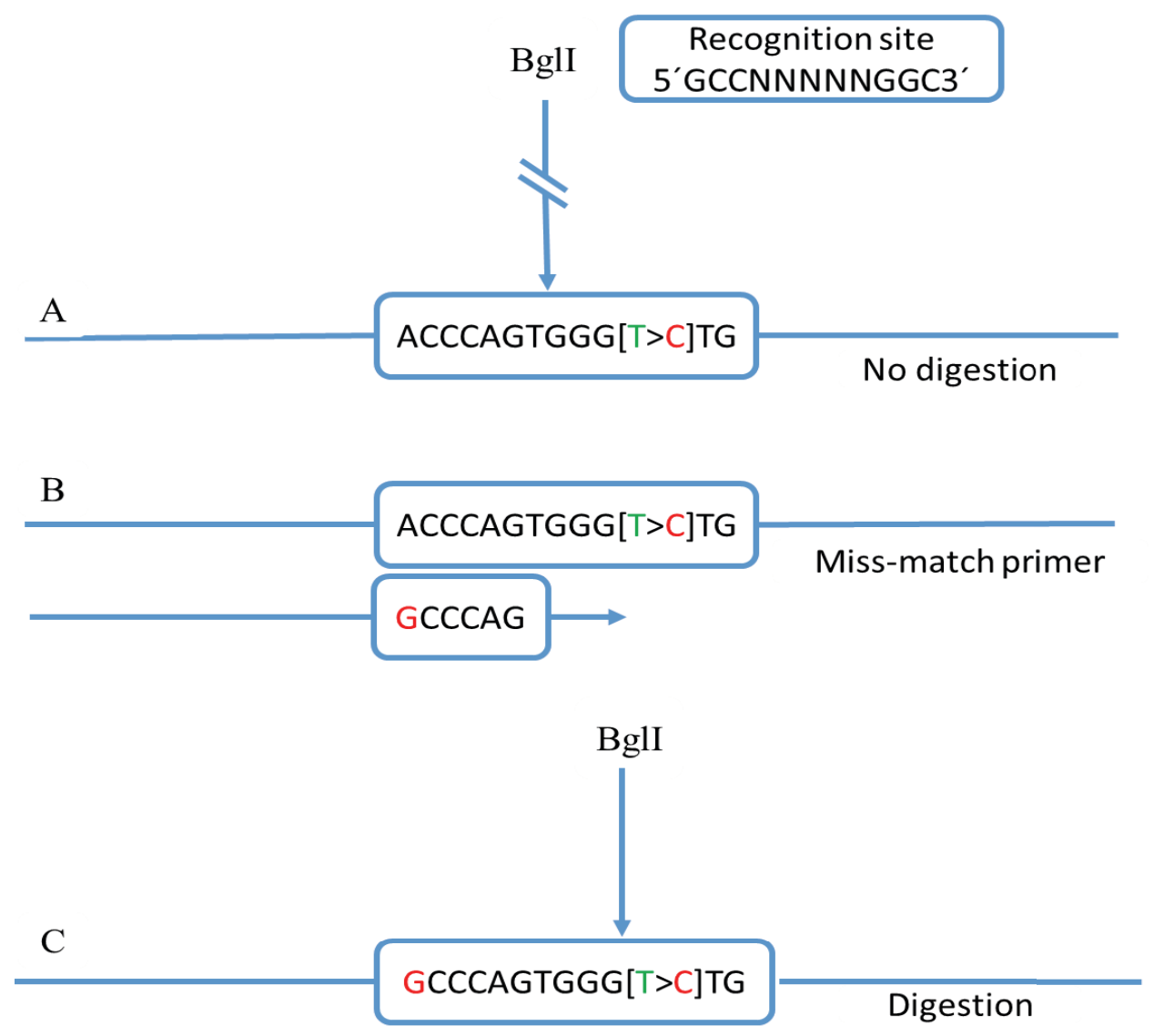

Figure 1 Mohammadi et al. 


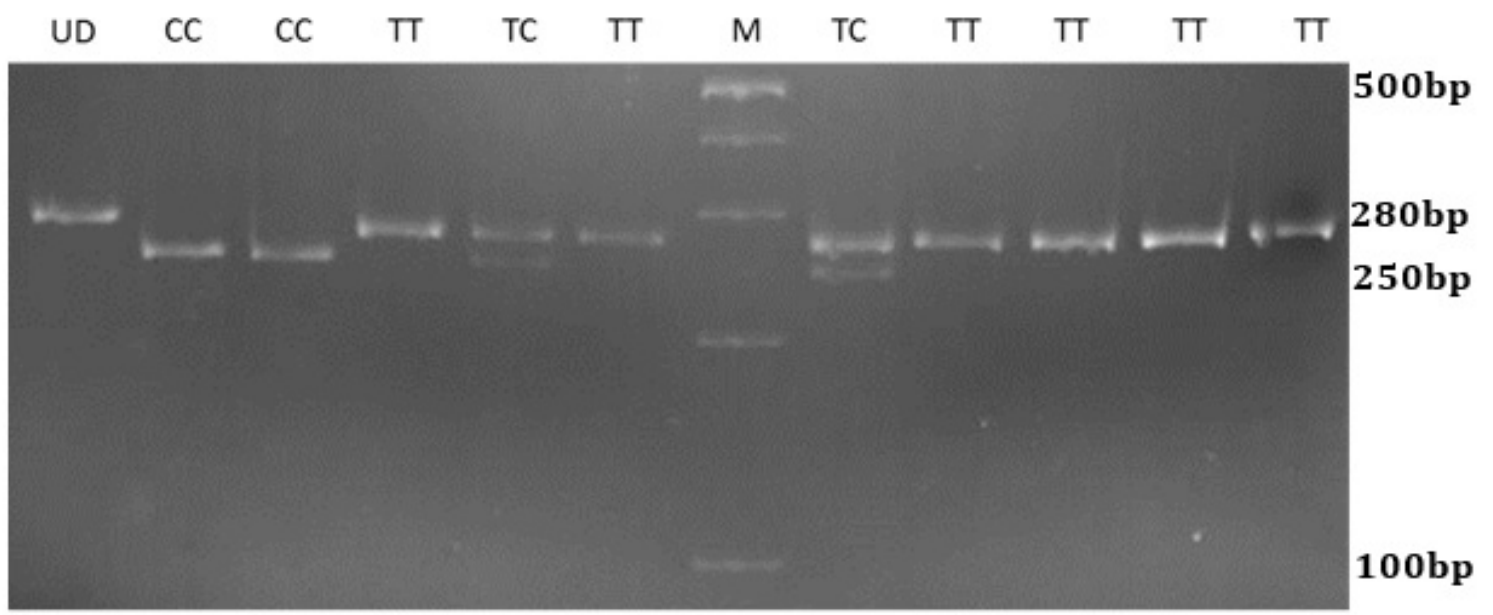

Figure 2 Mohammadi et al 


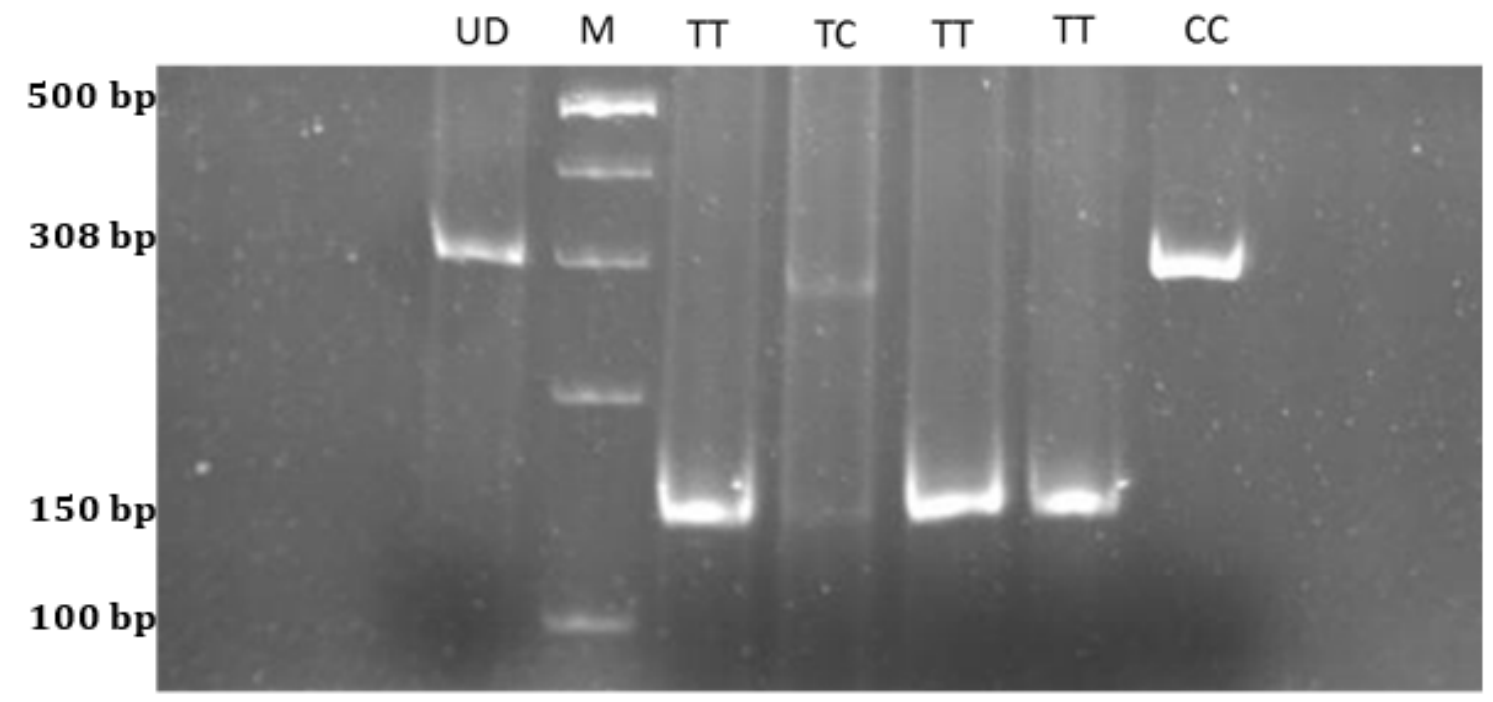

Figure 3 Mohammadi et al. 

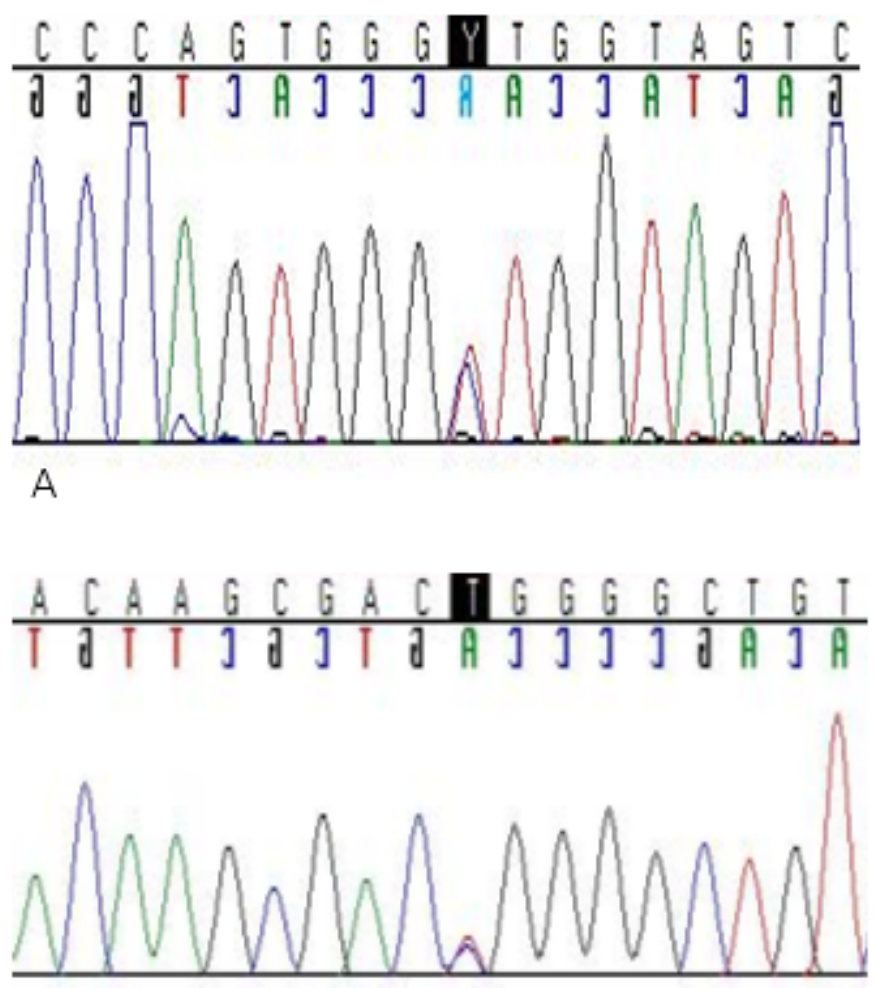

B

Figure 4 Mohammadi et al 
Table 1: clinical profiles of MS patient and controls.

\begin{tabular}{lll}
\hline & Patient: $n=188$ & Control: $n=204$ \\
\hline Female: male & $143: 45$ & $169: 35$ \\
Age (mean years \pm SD) & $34 \pm 8.96$ & $31 \pm 8.90$ \\
RR & 144 & - \\
SP & 36 & - \\
PP & 8 & - \\
EDSS (mean \pm SD) & $3.12 \pm 2.00$ & \\
\hline EDSS: Expanded Disability & Status Scale of McDonald's criteria; RR: relapsing- \\
remitting; SP: secondary progressive; PP: primary progressive.
\end{tabular}


Table 2: Genotypic and allelic frequencies of NPY SNPs in multiple sclerosis (MS) patients compared to healthy controls.

\begin{tabular}{|c|c|c|c|c|c|c|c|c|}
\hline \multirow{2}{*}{ SNP } & \multirow{2}{*}{$\begin{array}{l}\text { Genotypes } \\
\text { and alleles }\end{array}$} & \multicolumn{2}{|c|}{ Case } & \multicolumn{2}{|c|}{ Control } & \multirow{2}{*}{$\chi^{2}$} & \multirow{2}{*}{ OR $(95 \% \mathrm{CI})$} & \multirow{2}{*}{$P$ value } \\
\hline & & $\mathrm{n}$ & $\%$ & $\mathrm{n}$ & $\%$ & & & \\
\hline \multirow{8}{*}{$\begin{array}{l}N P Y \quad-485 \mathrm{~T}>\mathrm{C} \\
\text { Maj. Allele: } \mathrm{T} \\
\text { Min. Allele: } \mathrm{C}\end{array}$} & TT & 57 & 30 & 71 & 35 & - & 1.00 & - \\
\hline & $\mathrm{TC}$ & 86 & 46 & 103 & 50 & 0.029 & $1.040(0.662-1.633)$ & 0.865 \\
\hline & $\mathrm{CC}$ & 45 & 24 & 30 & 15 & 4.526 & $1.866(1.047-3.333)$ & 0.033 \\
\hline & $\mathrm{TC}+\mathrm{CC}$ & 131 & 70 & 133 & 65 & 0.895 & $1.227(0.803-1.875)$ & 0.344 \\
\hline & $\mathrm{TT}+\mathrm{TC}$ & 143 & 76 & 174 & 85 & - & 1.00 & - \\
\hline & $\mathrm{CC}$ & 45 & 24 & 30 & 15 & 5.387 & $1.825(1.094-3.046)$ & 0.02 \\
\hline & $\mathrm{T}$ & 200 & 53 & 245 & 60 & - & 1.00 & - \\
\hline & $\mathrm{C}$ & 176 & 47 & 163 & 40 & 3.749 & $1.323(0.996-1.756)$ & 0.053 \\
\hline \multirow{8}{*}{$\begin{array}{l}N P Y \_20 \mathrm{~T}>\mathrm{C} \\
\text { Maj. Allele: } \mathrm{T} \\
\text { Min. Allele: } \mathrm{C}\end{array}$} & TT & 175 & 93 & 190 & 93 & - & 1.00 & - \\
\hline & $\mathrm{TC}$ & 12 & 6.5 & 14 & 7 & 0.031 & $0.931(0.419-2.067)$ & 0.860 \\
\hline & $\mathrm{CC}$ & 1 & 0.5 & 0 & 0 & 1.083 & $0.994(0.993-1.005)$ & 0.298 \\
\hline & $\mathrm{TC}+\mathrm{CC}$ & 13 & 7 & 14 & 7 & 0.000 & $1.008(0.461-2.204)$ & 0.984 \\
\hline & $\mathrm{TT}+\mathrm{TC}$ & 187 & 99.5 & 204 & 100 & - & 1.00 & - \\
\hline & $\mathrm{CC}$ & 1 & 0.5 & 0 & 0 & 1.088 & $0.995(0.994-1.005)$ & 0.297 \\
\hline & $\mathrm{T}$ & 362 & 93.6 & 394 & 93.6 & - & 1.00 & - \\
\hline & $\mathrm{C}$ & 14 & 3.7 & 14 & 3.4 & 0.048 & $1.088(0.512-2.314)$ & 0.826 \\
\hline
\end{tabular}

The chi-square test was used to determine whether significant differences ( $P$ value) were observed when patient group compared with control group. $\mathrm{OR}=$ odds ratio; $\mathrm{CI}=$ confidence interval. Significant differences were observed in the genotype distribution of $N P Y_{-}-485 \mathrm{~T}>\mathrm{C}$ between MS patients and healthy controls. 
Table 3: Allelic and genotype frequencies of NPY $\_-485 \mathrm{~T}>\mathrm{C}$ SNP in MS patient subgroups compared with healthy controls.

\begin{tabular}{|c|c|c|c|c|c|c|c|c|c|c|c|}
\hline \multirow{5}{*}{$\begin{array}{l}N P Y \quad-485 \mathrm{~T}>\mathrm{C} \\
\text { Maj. Allele: T } \\
\text { Min. Allele: C }\end{array}$} & TT & 35 & 30 & 1.00 & & 33 & 1.00 & & 12.5 & 1.00 & \\
\hline & $\mathrm{CC}$ & 15 & 25 & $1.936(1.049-3.576)$ & 0.034 & 14 & $0.986(0.319-3.044)$ & 0.981 & 50 & $9.467(1.015-88.258)$ & 0.019 \\
\hline & $\mathrm{TC}+\mathrm{CC}$ & 65 & 70 & $1.213(0.768-1.916)$ & 0.407 & 67 & $1.068(0.504-2.261)$ & 0.864 & 87.5 & $3.737(0.451-30.977)$ & 0.191 \\
\hline & $\mathrm{T}$ & 60 & 52.8 & 1.00 & & 59.7 & 1.00 & & 31.3 & 1.00 & \\
\hline & $\mathrm{C}$ & 40 & 47.2 & $1.345(0.992-1.824)$ & 0.056 & 40.3 & $1.014(0.608-1.690)$ & 0.958 & 68.7 & $3.307(1.128-9.694)$ & 0.022 \\
\hline
\end{tabular}

The chi-square test was used to determine whether significant differences ( $P$ value) were observed when MS subgroups were compared with control group. RR: relapsing remitting; SP: secondary progressive; PP primary progressive course of disease. Significant difference was observed in the genotype distribution of SNP between RR MS subgroup and healthy control. Also, there was significant difference between PP MS subgroup and healthy control in related to the genotype and allelic distribution. 
Table 4: Three common haplotypes of two genotyped SNPs and their association with MS.

\begin{tabular}{|c|c|c|c|c|c|c|c|c|c|c|c|c|c|c|c|}
\hline & $N P Y{ }_{-}-485 \mathrm{~T}>\mathrm{C}$ & $N P Y \_20 \mathrm{~T}>\mathrm{C}$ & MS & Control & OR & $\begin{array}{c}P \\
\text { value }\end{array}$ & $\begin{array}{l}\text { RR } \\
\text { MS }\end{array}$ & OR & $\begin{array}{c}P \\
\text { value }\end{array}$ & $\begin{array}{c}\text { SP } \\
\text { MS }\end{array}$ & OR & $\begin{array}{c}P \\
\text { value }\end{array}$ & $\begin{array}{l}\text { PP } \\
\text { MS }\end{array}$ & OR & $\begin{array}{c}P \\
\text { value }\end{array}$ \\
\hline hap1 & $\mathrm{T}$ & $\mathrm{T}$ & 0.506 & 0.573 & 1.00 & - & 0.494 & 1.00 & - & 0.570 & 1.00 & - & 0.313 & 1.00 & - \\
\hline hap2 & $\mathrm{T}$ & $\mathrm{C}$ & 0.029 & 0.028 & $\begin{array}{c}1.015 \\
(0.467- \\
2.208)\end{array}$ & 0.970 & 0.032 & $\begin{array}{c}1.154 \\
(0.511- \\
2.607)\end{array}$ & 0.730 & 0.033 & $\begin{array}{c}1.095 \\
(0.302- \\
3.962)\end{array}$ & 0.890 & - & - & - \\
\hline hap3 & $\mathrm{C}$ & $\mathrm{T}$ & 0.460 & 0.392 & $\begin{array}{c}1.296 \\
(0.983- \\
1.709)\end{array}$ & 0.066 & 0.468 & $\begin{array}{c}1.363 \\
(1.013- \\
1.834)\end{array}$ & 0.041 & 0.390 & $\begin{array}{c}1.010 \\
(0.619- \\
1.646)\end{array}$ & 0.970 & 0.688 & $\begin{array}{c}3.096 \\
(1.056- \\
9.076)\end{array}$ & .031 \\
\hline
\end{tabular}

The chi-square test was used to determine whether significant differences ( $P$-value)

were observed when MS patients group and subgroups were compared with control healthy group. RR: relapsing remitting; SP: secondary progressive; PP primary progressive course of disease. Haplotype 3 (CT) is significantly higher in RR and PP MS when compared with healthy control group. 